\title{
Laboratory Selection and Assessment of Resistance Risk in Drosophila suzukii (Diptera: Drosophilidae) to Spinosad and Malathion
}

\author{
Joseph Onwusemu Disi and Ashfaq A. Sial *(1)
}

check for updates

Citation: Disi, J.O.; Sial, A.A. Laboratory Selection and Assessment of Resistance Risk in Drosophila suzukii (Diptera: Drosophilidae) to Spinosad and Malathion. Insects 2021, 12, 794. https://doi.org/10.3390/ insects12090794

Academic Editor: Antonio Biondi

Received: 2 July 2021

Accepted: 31 August 2021

Published: 4 September 2021

Publisher's Note: MDPI stays neutral with regard to jurisdictional claims in published maps and institutional affiliations.

Copyright: (C) 2021 by the authors Licensee MDPI, Basel, Switzerland. This article is an open access article distributed under the terms and conditions of the Creative Commons Attribution (CC BY) license (https:/ / creativecommons.org/licenses/by/ $4.0 /)$.
Department of Entomology, University of Georgia, Athens, GA 30302, USA; JOSEPH.DISI@uga.edu * Correspondence: ashsial@uga.edu; Tel.: +1-(706)-542-1320

Simple Summary: Continuous insecticide applications used to prevent fruit infestations by spottedwing drosophila (SWD), an invasive pest of soft-skinned fruits worldwide, can elevate the risk of resistance development in D. Suzukii field populations. However, proactive assessment of resistance risk using laboratory selection provides valuable information for development of sustainable resistance management strategies for SWD. After 10 and 11 generations of artificial selection of a colony of field-collected SWD for resistance against spinosad and malathion, a 7.55- and 2.23-fold resistance to spinosad and malathion was realized. A quantitative genetic approach used to estimate realized heritability $\left(h^{2}\right)$ of resistance shows that the risk of resistance in SWD populations exists against both spinosad and malathion, and a faster rate of resistance development is expected against spinosad. However, timely implementation of resistance management strategies can slow the development of resistance and prolong effective life of these insecticides against $D$. suzukii.

Abstract: Drosophila suzukii (Matsumura) is one of the most economically important pests of softskinned fruits worldwide. Repeated insecticide applications commonly used to prevent fruit infestations increase the risk of resistance development in D. suzukii. Assessment of resistance risk in D. suzukii using artificial selection can be valuable in developing proactive resistance management strategies to retain susceptibility in the field populations. Here, we artificially selected a colony of field-collected D. suzukii for resistance against spinosad and malathion. A quantitative genetic approach was then used to estimate realized heritability $\left(h^{2}\right)$ of resistance and predict the rates of resistance development. After 10 and 11 generations of selection, resistance to spinosad and malathion in D. suzukii females significantly increased by 7.55- and 2.23-fold, respectively. Based on the predicted rates of resistance development, assuming $h^{2}=0.14$ (mean $h^{2}$ of spinosad resistance in this study) and $90 \%$ of population was killed at each generation, 10 -fold increase in $\mathrm{LC}_{50}$ of D. suzukii females would be expected in nine generations for spinosad. However, 10 -fold increase in $\mathrm{LC}_{50}$ of $D$. suzukii females for malathion would be expected in 37 generations, assuming $h^{2}=0.08$ (mean $h^{2}$ of malathion resistance) and $90 \%$ of population was killed at each generation. These results indicate that the risk of resistance in D. suzukii populations exists against both spinosad and malathion. However, resistance would develop faster against spinosad as compared to malathion. Thus, resistance management strategies should be implemented proactively to maintain the effectiveness of these insecticides to control D. suzukii.

Keywords: spotted-wing drosophila; spinosyns; organophosphate; dose-response bioassays; resistance development; realized heritability

\section{Introduction}

Drosophila suzukii Matsumura (Diptera: Drosophilidae), commonly referred to as spotted-wing drosophila (SWD), has emerged as an economically important insect pest of soft-skinned fruits in many parts of the world including Europe, North America and Africa [1-4]. Female D. suzukii selectively lay eggs in ripening and ripe fruits where early 
instars complete their development within the fruit rendering the fruits unmarketable. Economic impact of this adaptive behavior of $D$. suzukii females in the berry industry is estimated to be over 421.5 million US dollar per year in worst-case infestation years [2]. In addition, farmers face significant economic losses if fruits are rejected in export sorting facilities because of detection of larvae in the fruits.

Control options tested or used for management of D. suzukii in places where economic pressures are found are mechanical exclusion [5], management of crop microclimate [6], and behavioral modifications [7-9]. However, due to extremely low tolerance for infested fruit in the market, preventative insecticide applications are the primary means to control D. suzukii [10-12]. Spinosad (spinosyn) and malathion (organophosphate) are among the two most used insecticides for control of D. suzukii [10-12]. While conventional fruit farmers may have an array of insecticides to choose from in addition to malathion [13], organic producers are limited to spinosad, being the only effective OMRI (Organic Materials Research Institute) approved insecticide for use in organic blueberry production. Malathion is widely used in D. suzukii control programs in blueberries because of its effectiveness and a very short pre-harvest interval of one day [3,10-12]. Therefore, berry fruit farmers make multiple applications of spinosad and malathion year in and year out, which increases the potential for resistance development in D. suzukii field populations. A recent study has already reported significant levels of resistance to spinosad in D. suzukii field populations collected from organic fruit farms in California [14]. In contrast, D. suzukii susceptibility to malathion was unaffected in a laboratory colony in British Columbia, Canada even after several generations of continuous exposure to malathion [15]. However, once developed, the ecological backlash of insecticide resistance can be costly due to the potential for control failures [16-22]. Armes et al. [16] reported huge control failures in India's cotton belt due to Helicoverpa armigera resistance to insecticides.

It is therefore important to assess resistance risk using flies collected from fields where these insecticides are frequently used against $D$. suzukii. Risk assessment will provide information on current resistance status and genetic basis of resistance, which is critical to develop integrated resistance management (IRM) strategies. Farmers will then be able to implement those strategies proactively to slow the development of resistance and continue to benefit from pest management products. The goal of this study was to assess the risk of resistance development to spinosad and malathion in D. suzukii populations to ensure that the products are effective in controlling D. suzukii. Specific objectives pursued were to: (1) artificially select D. suzukii for resistance to spinosad and malathion and (2) estimate realized heritability and predict rates of resistance development in D. suzukii against spinosad and malathion.

\section{Materials and Methods}

\subsection{Insects}

A total of five field populations of D. suzukii were collected after the 2017 field season's harvest from blueberry plantations located in four counties in Georgia, USA. Briefly, apple cider vinegar dispensed with paper towel in modified 32 oz plastic cup traps were placed on the border rows in blueberry fields. Traps were retrieved three days later, and live captured flies were aspirated and identified under the microscope in the laboratory. One of these populations was from an organic blueberry farm while the other four were collected from conventional commercial blueberry farms without prior history of spinosyns or malathion resistance [23]. To have maximum genetic variation after maintaining the colonies for two generations in the laboratory, 50 mated females from each of the five field populations were used to develop a mixed population. Flies from the mixed populations were used for the insecticide resistance selection in the laboratory. The D. suzukii colonies were reared on a standard insecticide free cornmeal media [24] in growth chamber at $24 \pm 1{ }^{\circ} \mathrm{C}, 65 \pm 5 \%$ $\mathrm{RH}$ and 14:10 h (L: D) photoperiod. 


\subsection{Selection of Drosophila suzukii Resistance to Spinosad and Malathion}

Selection was performed using glass vial method developed for adult $D$. suzukii contact bioassays with slight modifications [23,25]. The insecticides used were spinosad (Entrust ${ }^{\mathrm{TM}}$ 24 SC, Dow AgrowSciences LLC, Indianapolis, IN, USA) and malathion (Malathion 8F, Gowan Company LLC, Yuma, AZ, USA). Acetone was used to dissolve malathion while formulated spinosad was dissolved in $\mathrm{ddH}_{2} \mathrm{O}$ and $1266.6 \mu \mathrm{L} \mathrm{L}^{-1}$ of an adjuvant (Induce ${ }^{\mathrm{TM}}$ brand, Helena Chemical Company, Memphis, TN, USA). The concentrations used for the selections were $8.15 \mathrm{ppm}$ for malathion and 21.6-38.02 ppm for spinosad and have been shown to cause nearly $100 \%$ mortality in susceptible flies from a laboratory colony. These concentrations were developed from a series of preliminary laboratory assays conducted to optimize the rapid assessment protocol for detection of insecticide resistance (RAPID) assays previously reported in Van Timmeren et al. [23] and Gress and Zalom [14]. For malathion, $2 \mathrm{~mL}$ of insecticide was pipetted into a $500 \mathrm{~mL}$ glass bottle, whirled for about $30 \mathrm{~s}$ to coat inside surface of the bottle. The glass bottle and the content were placed on a hotdog roller for about $10 \mathrm{~min}$ to dry. On the other hand, formulated spinosad was dissolved in a water-induce mixture, a $2 \mathrm{~mL}$ measure was pipetted into a $500 \mathrm{~mL}$ bottle and whirled as described above. Unlike the bottles that were coated with malathion, heat was applied for $30 \mathrm{~min}$ to hasten the drying of spinosad-coated bottles. The next morning, 10 male and 10 female flies, 3-7 days old, were aspirated into $20 \mathrm{~mL}$ scintillation vials without insecticides in preparation to being released into the insecticides-treated bottles for maximum exposure. A total of 7000 flies (1:1 sex ratio) was released into thirty-five 500 $\mathrm{mL}$ insecticide-coated glass bottles without diet (i.e., 200 per bottle) in the beginning of the selection. Flies that survived after $3 \mathrm{~h}$ of exposure to malathion or $6 \mathrm{~h}$ of exposure to spinosad were transferred to plastic drosophila rearing bottles without insecticides, but with a thin layer of media to provide moisture. After $24 \mathrm{~h}$, dead flies were counted while survivors were moved to freshly made media without insecticide where they were allowed to reproduce. Offspring were again exposed in the insecticide treated bottles as described above. This process was repeated for a total of 10 rounds of selection for spinosad and 11 rounds of selection for malathion. Percentage of survivors were determined for every round of selection from the offspring.

\subsection{Dose-Response Bioassay}

Following previously developed $D$. suzukii susceptibility bioassay protocol with modifications, dose-response bioassays were performed with spinosad- and malathion-selected fly strains, and flies from the unselected mixed population were used as a reference susceptible population to determine any changes in susceptibility of the flies due to selection. Depending on the availability of flies, dose-response bioassays were performed for $\mathrm{F}_{3}$, $\mathrm{F}_{8}$ and $\mathrm{F}_{10}$ in the case of spinosad and $\mathrm{F}_{7}, \mathrm{~F}_{9}$ and $\mathrm{F}_{11}$ in the case of malathion. A total of 6-8 concentrations of each insecticide were used to conduct dose-response bioassays, which ranged from 3 to $15 \mathrm{ppm}$ for malathion and 3-300 ppm for spinosad. Briefly, $1 \mathrm{~mL}$ of insecticide was pipetted into the $20 \mathrm{~mL}$ scintillation vials, whirled for about $30 \mathrm{~s}$ to coat the inside surface of the vial, after which the content was dried as previously described for the selection bioassay. Five male and five female $D$. suzukii flies were first aspirated into insecticide-free $20 \mathrm{~mL}$ scintillation vials and gently released into the insecticide-treated vials. Mortality was assessed after $3 \mathrm{~h}$ of exposure to malathion and $6 \mathrm{~h}$ of exposure to spinosad in vials coated with malathion or spinosad. Live, moribund, or dead flies were counted. Moribund in this study was defined as inability of the flies to right themselves on their legs in $30 \mathrm{~s}$ after being flipped on their nota in scintillation vial. Moribund flies were recorded as dead for data analysis. The experiment was replicated three times per dilution concentration for a total of 90-105 flies per dose response bioassay.

\subsection{Data Analysis}

Mortality data were subjected to probit analysis using Polo plus (LeOra software) to determine median lethal concentrations $\left(\mathrm{LC}_{50}\right)$ values along with their corresponding $95 \%$ 
fiducial limits. The resistance ratio and their $95 \%$ confidence limits were calculated by dividing the $\mathrm{LC}_{50}$ of the selected strains of $D$. suzukii by the $\mathrm{LC}_{50}$ of the unselected mixed population. Resistance ratio was considered significantly different if the $95 \%$ confidence limits generated with mortality data from the selected strain did not overlap with that of the unselected mixed population. Unequal selection of males and females was observed in this study, and as a result separate estimation was made for both sexes throughout the paper to minimize bias that may be introduced by pooling mortality data between males and females.

\subsection{Estimation of Realized Heritability}

Realized heritability $\left(h^{2}\right)$ of $D$. suzukii selected for resistance to spinosad and malathion in the laboratory was calculated using the threshold trait analysis method developed by Tabashnik [26]. Thus, realized heritability $\left(h^{2}\right)=$ response to selection $(R) /$ selection differential (S).

Response to selection $(R)$ was calculated as:

$$
R=\log \left(\text { final } \mathrm{LC}_{50}\right)-\log \left(\text { initial } \mathrm{LC}_{50}\right) / n,
$$

where final $\mathrm{LC}_{50}$ is the $\mathrm{LC}_{50}$ computed after $n$ generations of selection for resistance to spinosad or malathion in this study and initial $\mathrm{LC}_{50}$ is the $\mathrm{LC}_{50}$ of the unselected mixed population (parental population) before selection.

The selection differential (S) was calculated as:

$$
\mathrm{S}=i \sigma_{p}
$$

where $i$ is the intensity of selection and $\sigma_{p}$ is the phenotypic standard deviation.

According to Tabashnik and McGaughey [27], selection intensity can be estimated using the equation:

$$
i=1.583-0.0193336 p+0.0000428 p^{2}+3.65194 / p,
$$

where $p$ is the percent survivorship after selection with spinosad or malathion.

The phenotypic standard deviation $\left(\sigma_{p}\right)$ was estimated as:

$$
\left.\sigma_{p}=[1 / 2 \text { (initial slope }+ \text { final slope })\right]^{-1},
$$

where initial and final slope values are those obtained from probit regression lines of parental population before selection and the offspring after $n$ generations of selection with spinosad or malathion.

\subsection{Projection of Number of Generations for 10-Fold Increase in Resistance Development}

The response of $D$. suzukii to selection in the laboratory can be used to predict risk of resistance development in terms of how many generations it may take for a 10-fold increase in resistance to the target pest control product. These quantitative genetics approach allows for estimation of potential control efficacy of an insecticide given the rate at which realized heritability increases or decreases during artificial selection in the laboratory [28]. Thus, by varying heritability and slope at different selection intensities, the number of generations $(G)$ required for a 10 -fold increase in resistance in D. suzukii selected to spinosad or malathion was calculated as the reciprocal of $R$ :

$$
\mathrm{G}=\mathrm{R}^{-1}=\left(h^{2} S\right)^{-1}
$$

The equation $\mathrm{Q}=\mathrm{R} / i$ was used to estimate the response quotient $(\mathrm{Q})$ necessary for comparing rates of resistance development against spinosad and malathion without reference to slope, which is not constant among insecticides [26]. $Q$ is valuable in evaluating the durability of any insecticide against any given pest population. 


\section{Results \\ 3.1. Selection of Drosophila suzukii Resistance to Spinosad and Malathion and Dose-Response Bioassay}

As a result of repeated exposure to spinosad or malathion over several generations, the susceptibility of the selected populations to the respective insecticides significantly decreased over time (Tables 1 and 2). Overall, the LC $_{50}$ of female D. suzukii for the tested insecticides, spinosad and malathion, was higher than that of male D. suzukii (Tables 1 and 2). The $\mathrm{LC}_{50}$ of spinosad-selected females was 50.72 and $65.73 \mathrm{ppm}$ in the $\mathrm{F}_{3}$ and $\mathrm{F}_{8}$ selected generations and then increased significantly to $167.25 \mathrm{ppm}$ in the $\mathrm{F}_{10}$ generation compared to the unselected mixed population females, thus representing a 7.55 -fold increase in $\mathrm{LC}_{50}$ (Table 1). Although the $\mathrm{LC}_{50}$ was generally lower for male flies compare with the females, a similar increasing trend in $\mathrm{LC}_{50}$ was observed in the tested generations with $\mathrm{LC}_{50}$ of 105.79 ppm recorded in the $\mathrm{F}_{10}$ male D. suzukii.

Table 1. Effect of spinosad residue on adult male and female D. suzukii from spinosad selected (SPN-sel) and unselected susceptible mixed field population.

\begin{tabular}{|c|c|c|c|c|c|}
\hline Selected Generation & Pop & Sex & Slope $( \pm$ SE) & $\mathrm{LC}_{50}(\mathrm{ppm})(95 \% \mathrm{FL})^{\dagger}$ & $\mathbf{R R}^{\mathbf{a}}$ \\
\hline & Unselected & Male & $2.05(0.38)$ & $20.39(8.78-41.59)$ & \\
\hline $\mathrm{F}_{3}$ & SPN-sel & Male & $3.88(1.14)$ & $26.00(19.00-36.93)$ & $1.28(0.25-0.67)$ \\
\hline $\mathrm{F}_{8}$ & SPN-sel & Male & $1.97(0.35)$ & $60.45(23.43-131.21)$ & $2.96(0.21-0.72)$ \\
\hline $\mathrm{F}_{10}$ & SPN-sel & Male & $2.91(0.54)$ & $105.79(71.11-153.15)$ & $5.19(0.15-0.44)$ \\
\hline & Unselected & Female & $2.27(0.50)$ & $22.14(7.16-52.88)$ & \\
\hline $\mathrm{F}_{3}$ & SPN-sel & Female & $1.96(0.34)$ & $50.72(21.28-100.82)$ & $2.29(0.13-0.41)$ \\
\hline $\mathrm{F}_{8}$ & SPN-sel & Female & $1.71(0.31)$ & $65.73(25.30-164.18)$ & $2.97(0.18-0.68)$ \\
\hline $\mathrm{F}_{10}$ & SPN-sel & Female & $2.47(0.54)$ & $167.25(95.62-387.14)$ & $7.55(0.11-0.33)$ \\
\hline
\end{tabular}

${ }^{\text {a }}$ Resistance ratio (RR) $=\mathrm{LC}_{50}$ of SPN-sel/LC 50 of unselected male and female mixed population, ${ }^{\dagger}=$ toxicity is significant when $95 \%$ fiducial limits did not overlap with unselected population.

Table 2. Effect of malathion residue on adult male and female D. suzukii from malathion selected (Mal-sel) and unselected susceptible mixed field population.

\begin{tabular}{|c|c|c|c|c|c|}
\hline Selected Generation & Pop & Sex & Slope $( \pm$ SE $)$ & $\mathrm{LC}_{50}(\mathrm{ppm})(95 \% \mathrm{FL})^{\dagger}$ & $\mathbf{R R}^{\mathrm{a}}$ \\
\hline & Unselected & Male & $3.92(0.75)$ & $2.72(1.71-3.29)$ & \\
\hline $\mathrm{F}_{7}$ & Mal-sel & Male & $3.76(0.69)$ & $3.23(1.39-4.67)$ & $1.19(0.41-0.85)$ \\
\hline $\mathrm{F}_{9}$ & Mal-sel & Male & $4.15(0.83)$ & $3.01(1.53-4.16)$ & $1.11(0.47-1.05)$ \\
\hline $\mathrm{F}_{11}$ & Mal-sel & Male & $5.72(1.02)$ & $5.49(3.55-7.28)$ & $2.02(0.49-0.87)$ \\
\hline & Unselected & Female & $4.70(1.03)$ & $3.50(2.23-4.55)$ & \\
\hline $\mathrm{F}_{7}$ & Mal-sel & Female & $3.95(0.74)$ & $3.72(2.07-5.02)$ & $1.06(0.58-1.13)$ \\
\hline $\mathrm{F}_{9}$ & Mal-sel & Female & $4.71(0.10)$ & $3.69(2.77-4.45)$ & $1.05(0.52-1.04)$ \\
\hline $\mathrm{F}_{11}$ & Mal-sel & Female & $8.58(1.64)$ & $7.81(6.61-9.12)$ & $2.23(0.48-0.78)$ \\
\hline
\end{tabular}

${ }^{a}$ Resistance ratio $(\mathrm{RR})=\mathrm{LC}_{50}$ of Mal-sel/ $\mathrm{LC}_{50}$ of unselected male and female mixed population; ${ }^{\dagger}=$ toxicity is significant when $95 \%$ fiducial limits did not overlap with unselected population.

For malathion-selected population, $\mathrm{LC}_{50}$ of malathion-selected females was recorded as $3.72 \mathrm{ppm}$ after 7 generations of selection which significantly increased to $7.81 \mathrm{ppm}$ after 11 generations of selection representing a 2.23-fold increase in $\mathrm{LC}_{50}$ (Table 2). Likewise, $\mathrm{LC}_{50}$ of malathion-selected males was recorded as $3.23 \mathrm{ppm}$ after 7 generations of selection which significantly increased to $5.49 \mathrm{ppm}$ after 11 generations of selection.

\subsection{Estimation of Realized Heritability}

After 10 generations of selection, realized heritability $\left(h^{2}\right)$ of spinosad resistance in female D. suzukii of the spinosad-selected population was estimated at 0.16 and $h^{2}$ of spinosad resistance in male D. suzukii was 0.14 . Similarly, after 11 generations of selection, $h^{2}$ of malathion resistance in female D. suzukii was estimated at 0.12 and $h^{2}$ of malathion resistance in male D. suzukii was 0.20 . Overall, $h^{2}$ of malathion resistance was slightly higher than $h^{2}$ of spinosad resistance in female $D$. suzukii of the selected populations, and vice versa in male D. suzukii (Figure 1). 


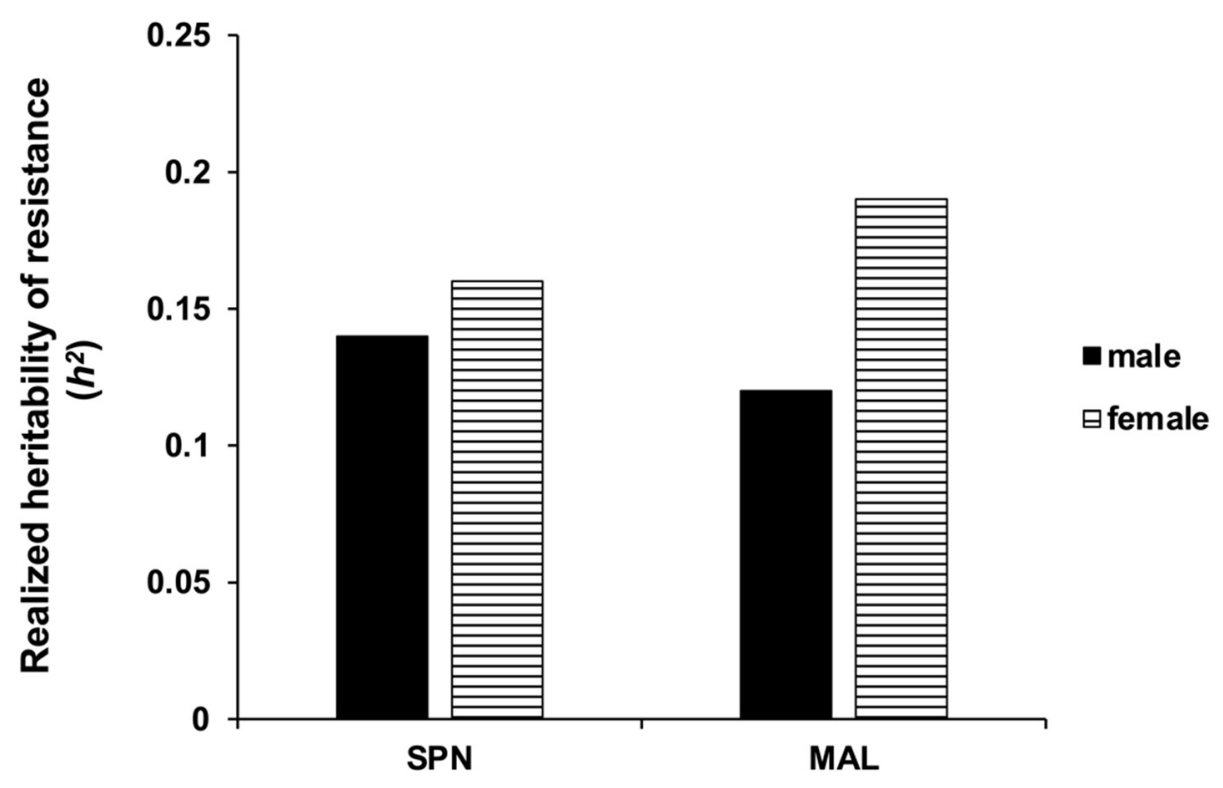

Figure 1. Realized heritability $\left(h^{2}\right)$ of resistance to spinosad and malathion in adult D. suzukii populations selected for resistance in the laboratory.

Over the course of these selection experiments, the mean values of response to selection (R) were 0.08 (female) and 0.05 (male), and the mean values of selection differential (S) were 0.67 (female) and 0.65 (male) for spinosad selection (Table 3). For malathion selection, the mean value of $\mathrm{R}$ was 0.01 (both female and male), while mean values of $\mathrm{S}$ were 0.21 (female) and 0.29 (male) (Table 4).

Table 3. Estimation of response to selection $(R)$ and selection differential $(S)$ of spinosad-selected adult population of D. suzukii.

\begin{tabular}{|c|c|c|c|c|c|c|c|c|c|}
\hline \multirow{2}{*}{$\begin{array}{l}\text { Selected } \\
\text { Generation }\end{array}$} & \multicolumn{4}{|c|}{ Estimation of Response to Selection } & \multicolumn{5}{|c|}{ Estimation of Selection Differential } \\
\hline & Sex & Initial $\mathrm{LC}_{50}(95 \% \mathrm{FL})$ & Final $\mathrm{LC}_{50}(95 \% \mathrm{FL})$ & $\mathbf{R}$ & $\mathbf{i}$ & Initial Slope $( \pm$ SE) & Final Slope ( \pm SE) & $\sigma_{p}$ & $\mathbf{s}$ \\
\hline $\mathrm{F}_{3}$ & Male & $20.39(8.78-41.59)$ & $26.00(19.00-36.93)$ & 0.01 & 1.74 & $2.05(0.38)$ & $3.88(1.14)$ & 0.34 & 0.59 \\
\hline $\mathrm{F}_{8}$ & Male & $20.39(8.78-41.59)$ & $60.45(23.43-131.21$ & 0.07 & 1.76 & $2.05(0.38)$ & $1.97(0.35)$ & 0.5 & 0.88 \\
\hline $\mathrm{F}_{10}$ & Male & $20.39(8.78-41.59)$ & 105.79 (71.11-153.15) & 0.07 & 1.21 & $2.05(0.38)$ & $2.91(0.54)$ & 0.4 & 0.49 \\
\hline $\mathrm{F}_{3}$ & Female & $22.14(7.16-52.88)$ & $50.72(21.28-100.82)$ & 0.12 & 1.45 & $2.27(0.50)$ & $1.96(0.34)$ & 0.47 & 0.69 \\
\hline $\mathrm{F}_{8}$ & Male & $20.39(8.78-41.59)$ & $60.45(23.43-131.21$ & 0.07 & 1.76 & $2.05(0.38)$ & $1.97(0.35)$ & 0.5 & 0.88 \\
\hline $\mathrm{F}_{10}$ & Female & $22.14(7.16-52.88)$ & $167.25(95.62-387.14)$ & 0.08 & 1.21 & $2.27(0.50)$ & $2.47(0.54)$ & 0.42 & 0.51 \\
\hline
\end{tabular}

Table 4. Estimation of response to selection $(R)$ and selection differential $(S)$ of malathion-selected adult population of D. suzukii.

\begin{tabular}{|c|c|c|c|c|c|c|c|c|c|}
\hline \multirow{2}{*}{$\begin{array}{l}\text { Selected } \\
\text { Generation }\end{array}$} & \multicolumn{4}{|c|}{ Estimation of Response to Selection } & \multicolumn{5}{|c|}{ Estimation of Selection Differential } \\
\hline & Sex & Initial LC50 (95\% FL) & Final LC50 (95\% FL) & $\mathbf{R}$ & $\mathbf{i}$ & Initial Slope $( \pm \mathrm{SE})$ & Final Slope $( \pm \mathbf{S E})$ & $\sigma_{p}$ & $\mathbf{s}$ \\
\hline $\mathrm{F}_{7}$ & Male & $2.72(1.71-3.29)$ & $3.23(1.39-4.67)$ & 0.01 & 1.27 & $3.92(0.75)$ & $3.76(0.69)$ & 0.26 & 0.33 \\
\hline $\mathrm{F}_{9}$ & Male & $2.72(1.71-3.29)$ & $3.01(1.53-4.16)$ & 0.008 & 1.1 & $3.92(0.75)$ & $4.15(0.83)$ & 0.25 & 0.27 \\
\hline $\mathrm{F}_{11}$ & Male & $2.72(1.71-3.29)$ & $5.49(3.55-7.28)$ & 0.03 & 1.23 & $3.92(0.75)$ & $5.72(1.02)$ & 0.21 & 0.26 \\
\hline $\mathrm{F}_{7}$ & Female & $3.50(2.23-4.55)$ & $3.72(2.07-5.02)$ & 0.004 & 1.01 & $4.70(1.03)$ & $3.95(0.74)$ & 0.23 & 0.23 \\
\hline $\mathrm{F}_{9}$ & Female & $3.50(2.23-4.55)$ & $3.69(2.77-4.45)$ & 0.003 & 1.08 & $4.70(1.03)$ & $4.71(0.10)$ & 0.21 & 0.23 \\
\hline $\mathrm{F}_{11}$ & Female & $3.50(2.23-4.55)$ & $7.81(6.61-9.12)$ & 0.03 & 1.04 & $4.70(1.03)$ & $8.58(1.64)$ & 0.15 & 0.16 \\
\hline
\end{tabular}

Overall, the response to selection (R) for malathion was lower as compared to the $\mathrm{R}$ for spinosad. The mean values of $\mathrm{Q}$ for malathion resistance in both male and female $(0.01)$ were also lower than those for spinosad resistance in female (0.06) and male (0.03) $D$. suzukii (Figure 2). 


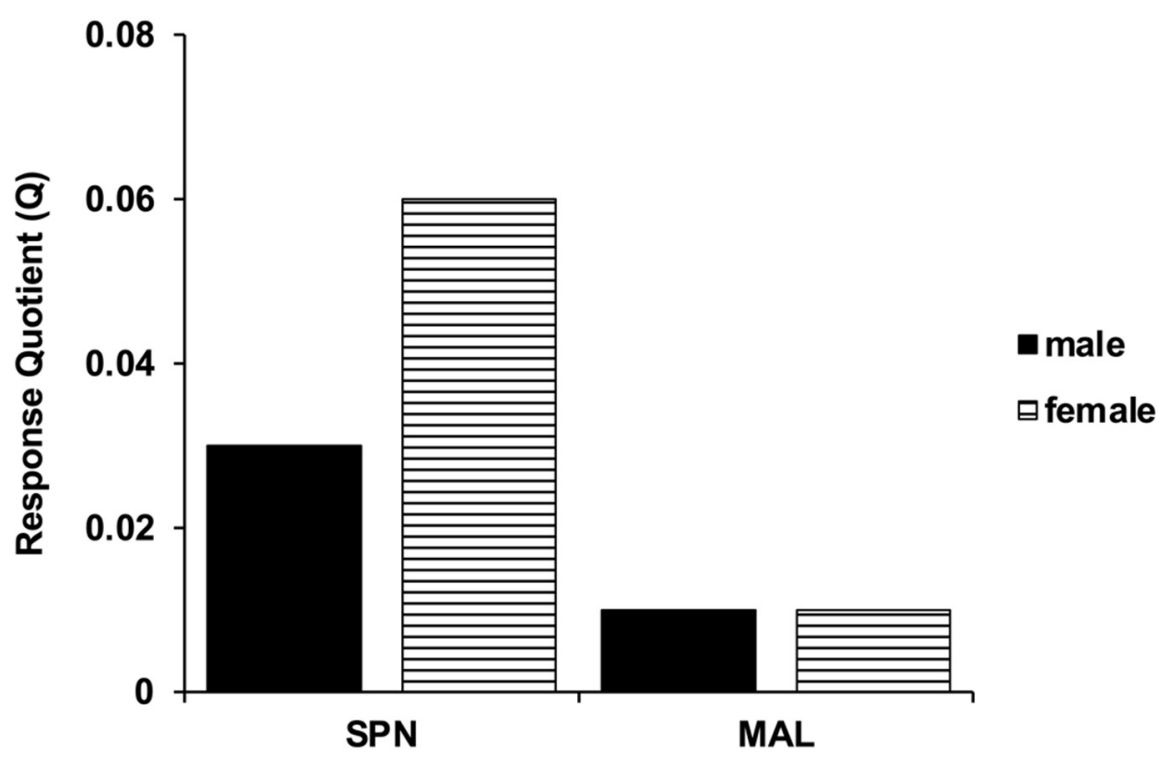

Figure 2. Response quotient $(\mathrm{Q})$ comparing rates of resistance against spinosad and malathion in adult D. suzukii populations selected for resistance in the laboratory.

\section{Discussion}

The significant decline in susceptibility of $D$. suzukii adults to spinosad and malathion, the two most used insecticides for fruits and vegetables in the United States, in this study indicates that resistance genes are present in the field populations that were used to establish the mixed colony even though no D. suzukii control failures associated with resistance have been reported yet [23]. Furthermore, the fact that the response quotient was higher for spinosad than malathion in the mixed field population in this study indicates that the resistance would develop at a faster rate against spinosad as compared to malathion.

This is the first report of D. suzukii adults' resistance to malathion in a laboratory selection study. After eleven generations of mass selection under high malathion intensity, susceptibility of malathion-selected D. suzukii adults decreased 2.23-fold compared to the unselected population. This finding corroborates previous report that showed that $D$. melanogaster resistance tended to increase more rapidly in high malathion selection intensity [29]. High selection intensity can eliminate unwanted alleles in selected populations even though use of high malathion concentration during selection bioassays has been reported to reduce genetic diversity due to very low survival rate [30,31]. Although we experienced high fly mortalities due to exposures to malathion in this study, we believe that the significant level of resistance obtained after only eleven generations of selection was due to genetic variation that was present in the population used to initiate the selection study. In contrast to our findings, the use of an inbred laboratory line of D. suzukii with little genetic variation did not permit selection of high malathion resistance even after 30 generations [15]. Our findings, though significant, do not represent a potential control failure with malathion. Rather, they serve as a caution that malathion resistance can emerge in field populations if proper IRM programs are not implemented.

Realized heritability estimates are important predictive indices to assess risk of resistance development in situations where there is limited information about the genetic basis of resistance [26]. In our study, the realized heritability $\left(h^{2}\right)$ values of 0.2 and 0.16 indicate that $20 \%$ of the variation in susceptibility of the selected population to malathion compared to $16 \%$ of the variation in susceptibility of the selected population to spinosad was caused by additive genetic variance in females. Even though, $h^{2}$ of malathion resistance was slightly higher than spinosad resistance in the female D. suzukii of the selected population, the majority of genetic variation in susceptibility to malathion was selected out of the population during the initial few rounds of selection due to high mortality. Consequently, the level of resistance to malathion was lower as compared to spinosad resistance in this study. 
For any population of $D$. suzukii, the predicted response to selection in terms of number of generations needed for a 10 -fold increase in $\mathrm{LC}_{50}(\mathrm{G})$ is directly proportional to slope assuming a constant heritability and inversely proportional to the heritability of resistance assuming a constant slope as shown in Figures 3 and 4. For instance, if $h^{2}=0.14$ (mean $h^{2}$ of spinosad resistance in this study) and $90 \%$ of population was killed at each generation, 10 -fold increase in $\mathrm{LC}_{50}$ of $D$. suzukii females would be expected in nine generations for spinosad at a slope of 2.2 (mean slope for spinosad in this study). However, everything else remaining the same, if the selection intensity decreases to a point where only $50 \%$ of the population is killed at each generation, 10 -fold increase in $\mathrm{LC}_{50}$ of $D$. suzukii females would be expected in 20 generations for spinosad. Similarly, if $h^{2}=0.08$ (mean $h^{2}$ of malathion resistance in this study) and $90 \%$ of population was killed at each generation, it will take 37 generations to see 10-fold increase in $\mathrm{LC}_{50}$ of $D$. suzukii females at a slope of 5.2 (mean slope for malathion in this study). However, everything else remaining the same, if the selection intensity decreases to a point where only $50 \%$ of the population is killed at each generation, it will take 81 generations to see 10 -fold increase in $\mathrm{LC}_{50}$ of $D$. suzukii females.

The response quotient is another parameter that can be used to compare the rates of resistance development in a population against different insecticides without reference to slope and assess the durability of various insecticides against a target pest. In the present study, the response quotient for resistance against spinosad was higher as compared to malathion. These results indicate that $D$. suzukii field populations will develop spinosad resistance at a faster rate as compared to malathion resistance. Thus, spinosad is more likely to lose efficacy in D. suzukii field populations in relatively shorter period of time compared to malathion.
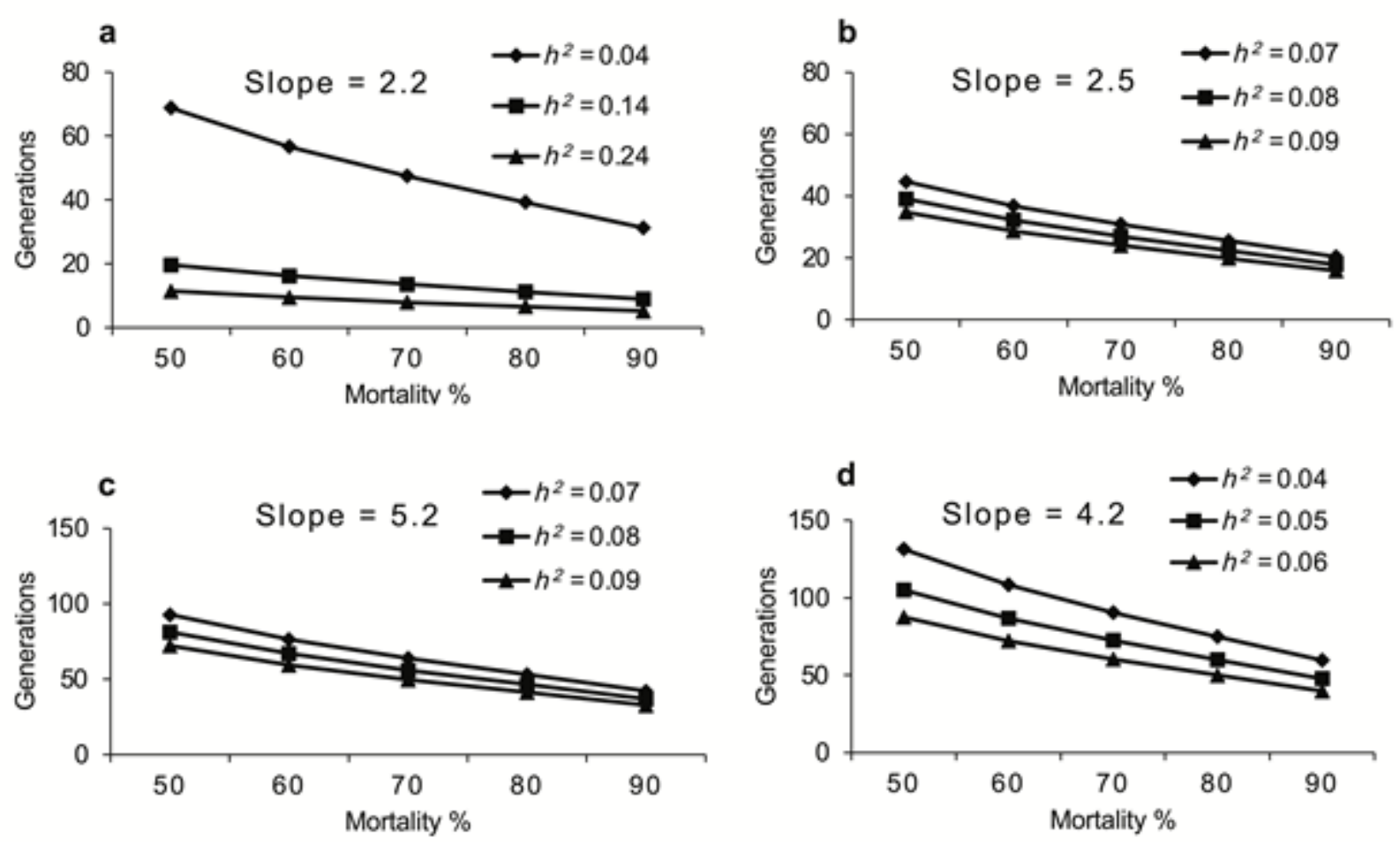

Figure 3. Effect of realized heritability on number of generations of D. suzukii required for a 10 -fold increase in $\mathrm{LC}_{50}$ of female exposed to spinosad (a), male exposed to spinosad (b), female exposed to malathion (c) and male exposed to malathion (d) at different selection intensities (i). 

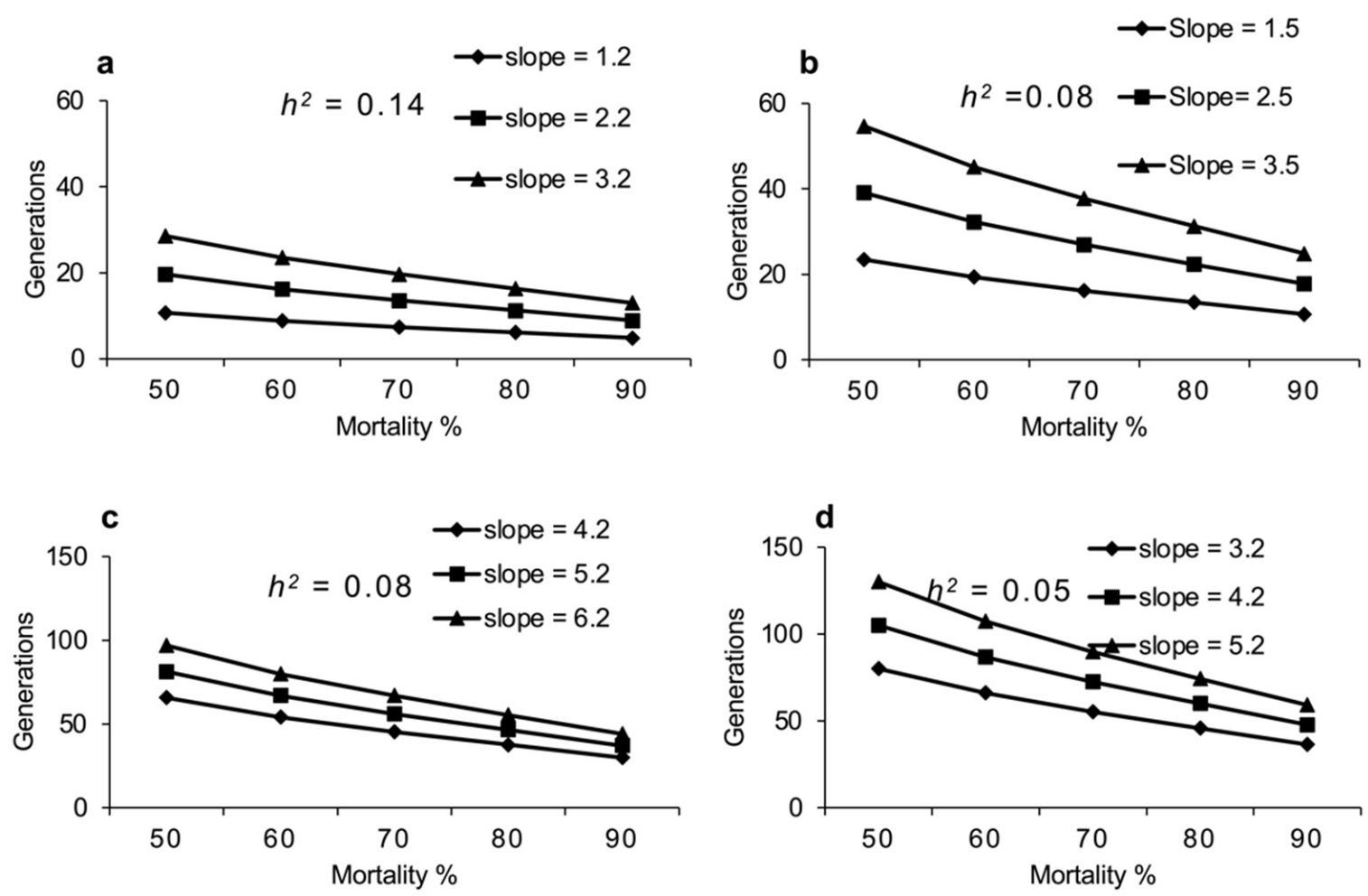

Figure 4. Effect of slope on number of generations of D. suzukii required for a 10-fold increase in LC $_{50}$ of female exposed to spinosad (a), male exposed to spinosad (b), female exposed to malathion (c) and male exposed to malathion (d) at different selection intensities (i).

Furthermore, in contrast with $h^{2}$ estimates reported for male spinosad-selected D. suzukii in California organic orchards [14] and in male Oriental fruit moth [32], our study showed that $h^{2}$ was generally higher in female compared with male, in both spinosad- and malathionselected strains. It is presently unknown how the sex-specific effects of insecticides contribute to heritability of resistance in field populations of D. suzukii. Male flies are killed relatively faster than female cohorts exposed to similar concentration of insecticides, possibly because of small body size [23,33]. Autosomal inheritance of malathion and spinosad resistance has been reported in the Oriental fruit fly Bactrocera dorsalis [34], but female-linked spinosad resistance has also been documented in the house fly Musca domestica L. [35]. Future studies are needed to understand the role of sex-linkage in D. suzukii resistance to insecticides.

Resistance is more difficult to actualize when selection is started from inbred insect lines with little genetic variation than a more heterogeneous population with more genetic variation [26,30]. In our study, we found high and low slope estimates against malathion and spinosad selected populations, respectively. This finding may explain the slower rate of resistance development against malathion than spinosad. Furthermore, fly population from spinosad-sprayed fields may have had higher selection pressure as organic fruit farmers make multiple spinosad applications during the growing season due to limited chemistries to rotate unlike conventional farming systems, where growers can rotate between chemistries. The relatively quick response of this mixed population selected with spinosad in this study reflects a high risk for resistance development against spinosad in $D$. suzukii populations in the field. Unlike other major berry production regions in the United States [14], we have not seen any reports of control failures of D. suzukii associated to the use of spinosad in Georgia small fruit production systems.

Our findings present an early warning for organic blueberry growers and pest managers that increased effort in resistance management strategies is needed to continue to benefit from the effectiveness of spinosad in management of D. suzukii. Furthermore, given that $D$. suzukii can go over 13 generations in a year in warmer regions of the United 
States [36], blueberry farmers should adhere to best management practices to continue to benefit from malathion as the slower rate of resistance development to malathion observed in this study is not an absence of resistance. Moreover, caution is needed in extrapolating results from a laboratory selection to field situation because every field population is different in terms of genetic variance and the exposure intensity, and laboratory data may not accurately predict resistance occurrence in actual field situations $[37,38]$.

In conclusion, our study clearly showed that statistically significant levels of resistance to spinosad and malathion were developed in D. suzukii after only 10 and 11 generations of selection as compared to the unselected mixed population. This suggests that resistance alleles are present in the field populations even though control failures from spinosad and malathion applications have not been reported yet. The presence of resistance alleles coupled with extreme dependence on spinosad and malathion as control tools for D. suzukii infestations indicate that the risk of resistance development in D. suzukii field populations against malathion and spinosad is high. For an organism that completes a generation within 8-10 days at optimal temperature of around $25^{\circ} \mathrm{C}$, multiple generations can be exposed to repeated applications of malathion and spinosad based on their current used patterns to control D. suzukii in blueberries. Such repeated exposure to these insecticides further increases the likelihood of resistance development in field populations of D. suzukii. In similar situations, high levels of field-evolved resistance has been documented in other species including Heliothis armigera, Bactrocera oleae, and Anthonomus grandis [8,10,11]. It is therefore critical to continue to monitor $D$. suzukii field populations for resistance and at the same time proactively implement IRM strategies by rotating insecticides with different modes of action into D. suzukii season-long management programs $[3,13,15]$. Further studies should proactively determine resistance mechanisms such that scientifically based IRM programs are implemented to prolong the effective life of both insecticides extremely important for $D$. suzukii management in organic and conventional berry production systems in the United States. As D. suzukii adults can move between blueberry fields and potential wild hosts in the surrounding wooded areas, which may serve as untreated refuge, future studies should investigate the impact of such movement on rates of resistance development and persistence of resistance genes in field populations.

Author Contributions: J.O.D. and A.A.S. conceived the experiments. J.O.D. designed and performed the experiments and analyzed the data. J.O.D. and A.A.S. wrote the manuscript. Both authors have read and agreed to the published version of the manuscript.

Funding: This research was supported by funding from the USDA Specialty Crops Research Initiative (Award \# 2015-51181-24252), the USDA Organic Agriculture Research and Extension Initiative (Award \# 2018-51300-28434), Extension Implementation Program (Award \# 2017-70006-27202), Georgia Blueberry Growers Association, and Georgia Agricultural Commodity Commission for Blueberries.

Institutional Review Board Statement: Not applicable.

Acknowledgments: We would like to thank members of Fruit Entomology Lab, University of Georgia for helping in aspiration of flies used in the initial resistance selection bioassays. This research was supported by funding from the USDA Specialty Crops Research Initiative (Award \# 2015-51181-24252), the USDA Organic Agriculture Research and Extension Initiative (Award \# 201851300-28434), Extension Implementation Program (Award \# 2017-70006-27202), Georgia Blueberry Growers Association, and Georgia Agricultural Commodity Commission for Blueberries. We also thank the grower collaborators from Georgia for allowing us access to their farms to collect $D$. suzukii field populations.

Conflicts of Interest: The authors declare no conflict of interest. 


\section{References}

1. Asplen, M.K.; Anfora, G.; Biondi, A.; Choi, D.S.; Chu, D.; Daane, K.M.; Gibert, P.; Gutierrez, A.P.; Hoelmer, K.A.; Hutchison, W.D.; et al. Invasion biology of spotted wing Drosophila (Drosophila suzukii): A global perspective and future priorities. J. Pest Sci. 2015, 88, 469-494. [CrossRef]

2. Bolda, M.P.; Goodhue, R.E.; Zalom, F.G. Spotted Wing Drosophila: Potential economic impact of a newly established pest. Agric. Resour. Econ. Updat. Univ. Calif. Giannini Found. 2010, 13, 5-8. [CrossRef]

3. Boughdad, A.; Haddi, K.; El Bouazzati, A.; Nassiri, A.; Tahiri, A.; El Anbri, C.; Eddaya, T.; Zaid, A.; Biondi, A. First record of the invasive spotted wing Drosophila infesting berry crops in Africa. J. Pest Sci. 2021, 94, 261-271. [CrossRef]

4. Walsh, D.B.; Bolda, M.P.; Goodhue, R.E.; Dreves, A.J.; Lee, J.; Bruck, D.J.; Walton, V.M.; O’Neal, S.D.; Zalom, F.G. Drosophila suzukii (Diptera: Drosophilidae): Invasive Pest of Ripening Soft Fruit Expanding its Geographic Range and Damage Potential. J. Integr. Pest Manag. 2011, 2, G1-G7. [CrossRef]

5. Leach, H.; Van Timmeren, S.; Isaacs, R. Exclusion Netting Delays and Reduces Drosophila suzukii (Diptera: Drosophilidae) Infestation in Raspberries. J. Econ. Entomol. 2016, 109, 2151-2158. [CrossRef]

6. Schöneberg, T.; Arsenault-benoit, A.; Taylor, C.M.; Butler, B.R.; Dalton, D.T.; Walton, V.M.; Petran, A.; Rogers, M.A.; Diepenbrock, L.M.; Burrack, H.J.; et al. Agriculture, Ecosystems and Environment Pruning of small fruit crops can affect habitat suitability for Drosophila suzukii. Agric. Ecosyst. Environ. 2020, 294, 106860. [CrossRef]

7. Yousef, M.; Aranda-Valera, E.; Quesada-Moraga, E. Lure-and-infect and lure-and-kill devices based on Metarhizium brunneum for spotted wing Drosophila control. J. Pest Sci. 2018, 91, 227-235. [CrossRef]

8. Tait, G.; Kaiser, C.; Rossi-Stacconi, M.V.; Dalton, D.T.; Anfora, G.; Walton, V.M. A food-grade gum as a management tool for Drosophila suzukii. Bull. Insectology 2018, 71, 295-307.

9. Rossi Stacconi, M.V.; Tait, G.; Rendon, D.; Grassi, A.; Boyer, G.; Nieri, R.; Walton, V.M. Gumming up the Works: Field Tests of a New Food-Grade Gum as Behavioral Disruptor for Drosophila suzukii (Diptera: Drosophilidae). J. Econ. Entomol. 2020, 113, 1872-1880. [CrossRef]

10. Santoiemma, G.; Tonina, L.; Marini, L.; Duso, C. Integrated management of Drosophila suzukii in sweet cherry orchards. Entomol. Generalis 2020, 40, 297-305. [CrossRef]

11. Klick, J.; Yang, W.Q.; Lee, J.C.; Bruck, D.J. Reduced spray programs for Drosophila suzukii management in berry crops. Int. J. Pest Manag. 2016, 62, 368-377. [CrossRef]

12. Haye, T.; Girod, P.; Cuthbertson, A.G.S.; Wang, X.G.; Daane, K.M.; Hoelmer, K.A.; Baroffio, C.; Zhang, J.P.; Desneux, N. Current SWD IPM tactics and their practical implementation in fruit crops across different regions around the world. J. Pest Sci. 2016, 89, 643-651. [CrossRef]

13. Van Timmeren, S.; Mota-Sanchez, D.; Wise, J.C.; Isaacs, R. Baseline susceptibility of spotted wing Drosophila (Drosophila suzukii) to four key insecticide classes. Pest Manag. Sci. 2018, 74, 78-87. [CrossRef]

14. Gress, B.E.; Zalom, F.G. Identification and risk assessment of spinosad resistance in a California population of Drosophila suzukii. Pest Manag. Sci. 2019, 75, 1270-1276. [CrossRef]

15. Smirle, M.J.; Zurowski, C.L.; Ayyanath, M.M.; Scott, I.M.; MacKenzie, K.E. Laboratory studies of insecticide efficacy and resistance in Drosophila suzukii (Matsumura) (Diptera: Drosophilidae) populations from British Columbia, Canada. Pest Manag. Sci. 2017, 73, 130-137. [CrossRef] [PubMed]

16. Armes, N.J.; Jadhav, D.R.; Bond, G.S.; King, A.B.S. Insecticide resistance in Helicoverpa armigera in South India. Pestic. Sci. 1992, 34, 355-364. [CrossRef]

17. Brouqui, P.; Parola, P.; Raoult, D. Insecticide resistance in mosquitoes and failure of malaria control. Expert Rev. Anti. Infect. Ther. 2012, 10, 1379-1381. [CrossRef] [PubMed]

18. Daly, J.C. Insecticide resistance in Heliothis armigera in Australia. Pestic. Sci. 1988, 23, 165-176. [CrossRef]

19. Horowitz, A.R.; Weintraub, P.G.; Ishaaya, I. Status of pesticide resistance in arthropod pests in Israel. Phytoparasitica 1998, 26, 231-240. [CrossRef]

20. Kakani, E.G.; Zygouridis, N.E.; Tsoumani, K.T.; Seraphides, N.; Zalom, F.G.; Mathiopoulos, K.D. Spinosad resistance development in wild olive fruit fly Bactrocera oleae (Diptera: Tephritidae) populations in California. Pest Manag. Sci. 2010, 66, 447-453. [CrossRef] [PubMed]

21. Oliveira-Marra, S.O.D.; Guedes, R.N.C.; Bastos, C.S.; Marra, P.H.A.; Vivan, L.M.; de Moura Zanine, A. Insecticide resistance and control failure likelihood among populations of the boll weevil (Anthonomus grandis) from mato grosso (brazil). Acta Sci. Agron. 2019, 41, 1-7. [CrossRef]

22. Su, J.; Lai, T.; Li, J. Susceptibility of field populations of Spodoptera litura (Fabricius) (Lepidoptera: Noctuidae) in China to chlorantraniliprole and the activities of detoxification enzymes. Crop Prot. 2012, 42, 217-222. [CrossRef]

23. Van Timmeren, S.; Sial, A.A.; Lanka, S.K.; Spaulding, N.R.; Isaacs, R. Development of a rapid assessment method for detecting insecticide resistance in spotted wing Drosophila (Drosophila suzukii Matsumura). Pest Manag. Sci. 2019, 75, 1782-1793. [CrossRef]

24. Jaramillo, S.L.; Mehlferber, E.; Moore, P.J. Life-history trade-offs under different larval diets in Drosophila suzukii (Diptera: Drosophilidae). Physiol. Entomol. 2015, 40, 2-9. [CrossRef]

25. Disi, J.O.; Van Timmeren, S.; Gress, B.; Zalom, F.; Isaacs, R.; Sial, A. Insecticide residue longevity for on-site screening of Drosophila suzukii (Matsumura) resistance. Pest Manag. Sci. 2020, 76, 2918-2924. [CrossRef] 
26. Tabashnik, B.E. Resistance Risk Assessment: Realized Heritability of Resistance to Bacillus thuringiensis in Diamondback Moth (Lepidoptera: Plutellidae), Tobacco Budworm (Lepidoptera: Noctuidae), and Colorado Potato Beetle (Coleoptera: Chrysomelidae). J. Econ. Entomol. 1992, 85, 1551-1559. [CrossRef]

27. Tabashnik, B.E.; McGaughey, W.H. Resistance risk assessment for single and multiple insecticides: Responses of indianmeal moth (Lepidoptera: Pyralidae) to Bacillus thuringiensis. J. Econ. Entomol. 1994, 87, 834-841. [CrossRef]

28. Tabashnik, B.E.; Cushing, N.L. Quantitative Genetic Analysis of Insecticide Resistance: Variation in Fenvalerate Tolerance in a Diamondback Moth (Lepidoptera: Plutellidae) Population. J. Econ. Entomol. 1989, 82, 5-10. [CrossRef]

29. Singh, R.; Morton, R.A. Selection for malathion-resistance in Drosophila melanogaster. Can. J. Genet. Cytol. 1981, 23, 355-369. [CrossRef] [PubMed]

30. Crow, J.F. Genetics of Insect Resistance to Chemicals. Annu. Rev. Entomol. 1957, 2, 227-246. [CrossRef]

31. Crow, J.F. Analysis of a DDT-Resistant Strain of Drosophila. J. Econ. Entomol. 1954, 47, 393-398. [CrossRef]

32. Kanga, L.H.B.; Pree, D.J.; Plapp, F.W.; Van Lier, J.L. Sex-linked altered acetylcholinesterase resistance to carbamate insecticides in adults of the Oriental fruit moth, Grapholita molesta (Lepidoptera: Tortricidae). Pestic. Biochem. Physiol. 2001, 71, 29-39. [CrossRef]

33. Pluthero, F.G.; Threlkeld, S.F. Genetic differences in malathion avoidance and resistance in Drosophila melanogaster. J. Econ. Entomol. 1981, 74, 736-740. [CrossRef] [PubMed]

34. Wang, L.L.; Feng, Z.J.; Li, T.; Lu, X.P.; Zhao, J.J.; Niu, J.Z.; Smagghe, G.; Wang, J.J. Inheritance, realized heritability, and biochemical mechanisms of malathion resistance in Bactrocera dorsalis (Diptera: Tephritidae). J. Econ. Entomol. 2016, 109, 299-306. [CrossRef]

35. Markussen, M.D.K.; Kristensen, M. Spinosad resistance in female Musca domestica L. from a field-derived population. Pest Manag. Sci. 2012, 68, 75-82. [CrossRef] [PubMed]

36. Tochen, S.; Dalton, D.T.; Wiman, N.; Hamm, C.; Shearer, P.W.; Walton, V.M. Temperature-related development and population parameters for Drosophila suzukii (Diptera: Drosophilidae) on cherry and blueberry. Environ. Entomol. 2014, 43, 501-510. [CrossRef]

37. Gerber, A.S.; Donald, P. Field experiments and natural Experiments: One definition of field experimentation. In The Oxford Handbook of Political Science; Oxford University Press: Oxford, UK, 2013; pp. 1-28. [CrossRef]

38. De Keyser, R.; Cassidy, C.; Laban, S.; Gopal, P.; Pickett, J.A.; Reddy, Y.K.; Prasad, M.; Prasad, G.; Chirukandoth, S.; Senthilven, K.; et al. Insecticidal effects of deltamethrin in laboratory and field populations of Culicoides species: How effective are host-contact reduction methods in India? Parasites Vectors 2017, 10, 54. [CrossRef] [PubMed] 